\title{
Secondary organic aerosol formation from photooxidation of furan: effects of NOx level and humidity
}

\author{
Xiaotong Jiang ${ }^{1}$, Narcisse T. Tsona ${ }^{1}$, Long $\mathrm{Jia}^{2}$, Shijie Liu ${ }^{1}$, Yongfu $\mathrm{Xu}^{2}$, Lin $\mathrm{Du}^{1}$
}

${ }^{1}$ Environment Research Institute, Shandong University, Qingdao, 266237, China

${ }^{2}$ State Key Laboratory of Atmospheric Boundary Layer Physics and Atmospheric Chemistry, Institute of Atmospheric Physics, Chinese Academy of Sciences, Beijing, 100029, China

Correspondence to: Lin Du (lindu@sdu.edu.cn)

\section{Supplementary material}




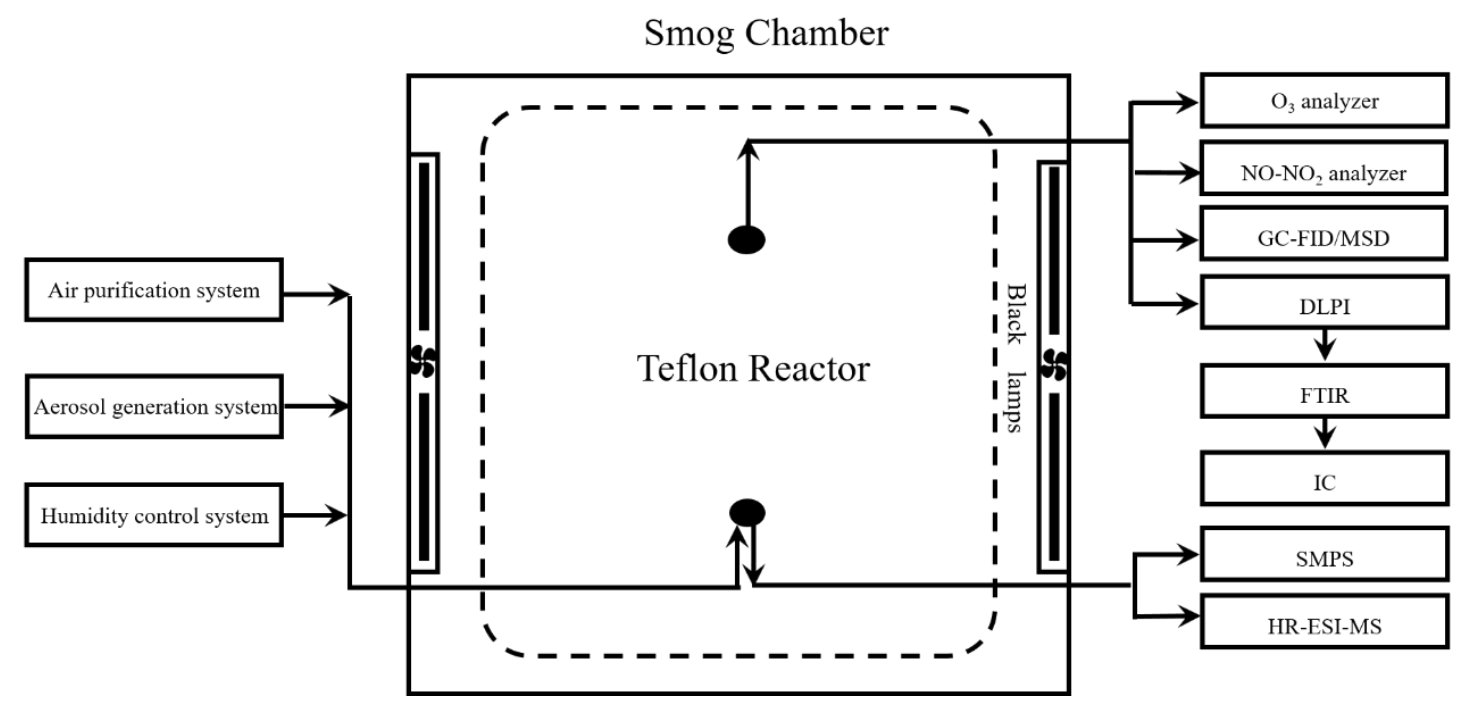

Figure S1: Schematic of the experimental set-up employed in this study.

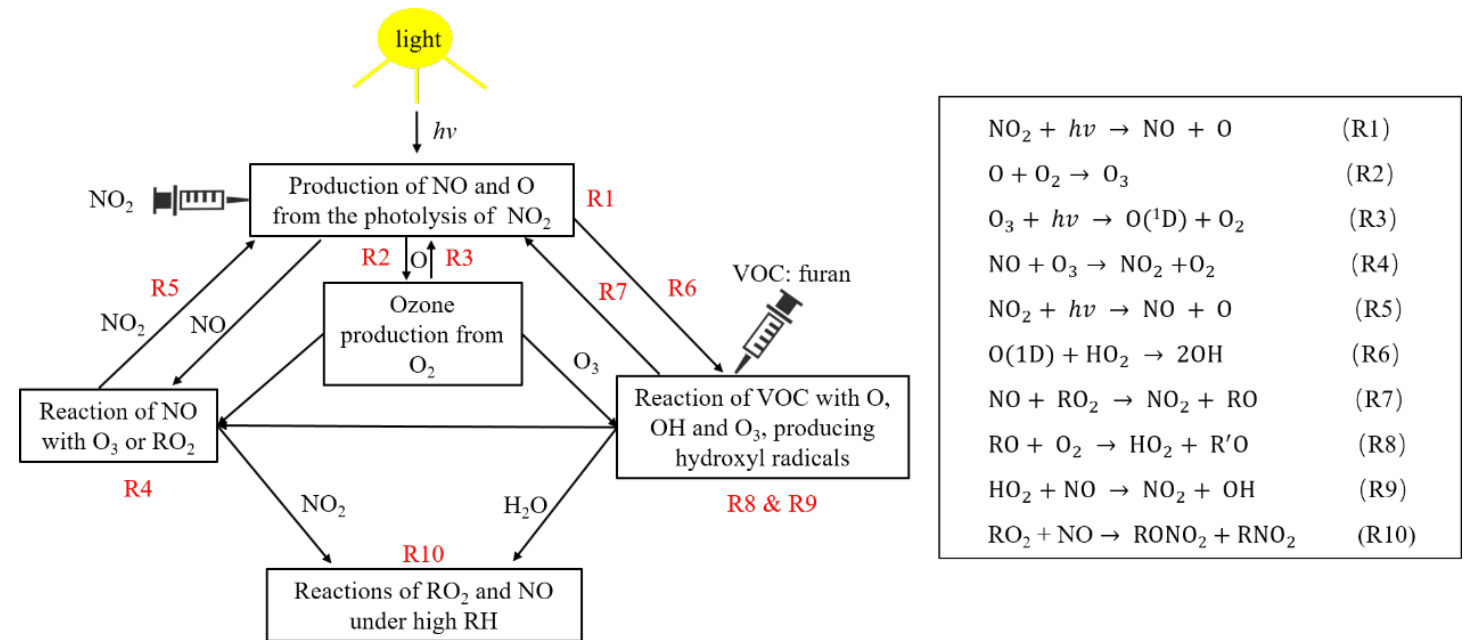

Figure S2: Major gas phase inorganic chemical reactions during the experiments. 

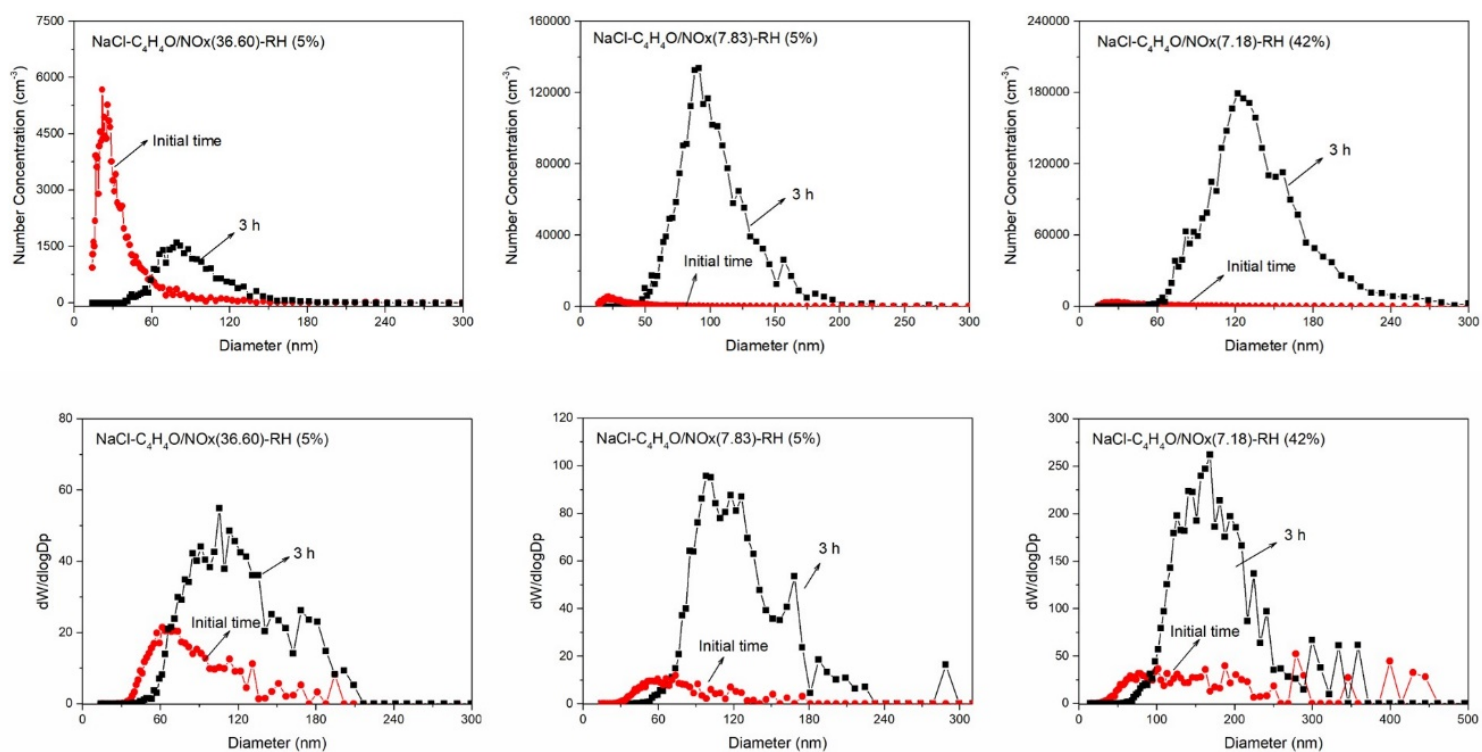

Figure S3: Variations of particle size distribution of number and mass concentrations in the beginning of the experiment and at the 3-h time point under different experimental conditions. Since the particle wall loss has a weak RH dependence in our chamber, a mean value $4.7 \times$ $10^{-5} \mathrm{~s}^{-1}$ wall loss correction was used. A density of $1.4 \mathrm{~g} \mathrm{~m}^{-3}$ was used in SMPS. 

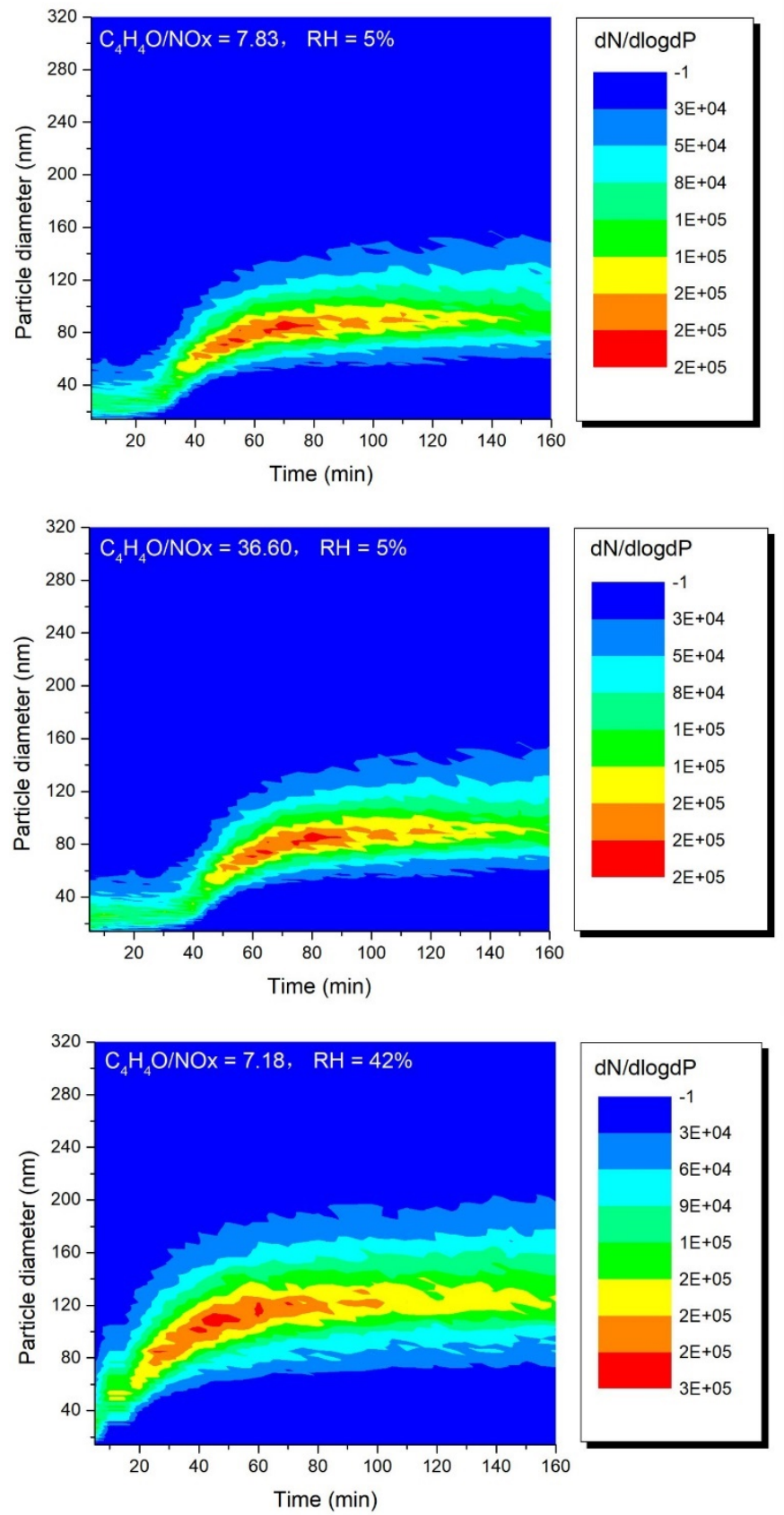

Time (min)

Figure S4: Contour plots of SOA bursts formed under different experimental conditions. 

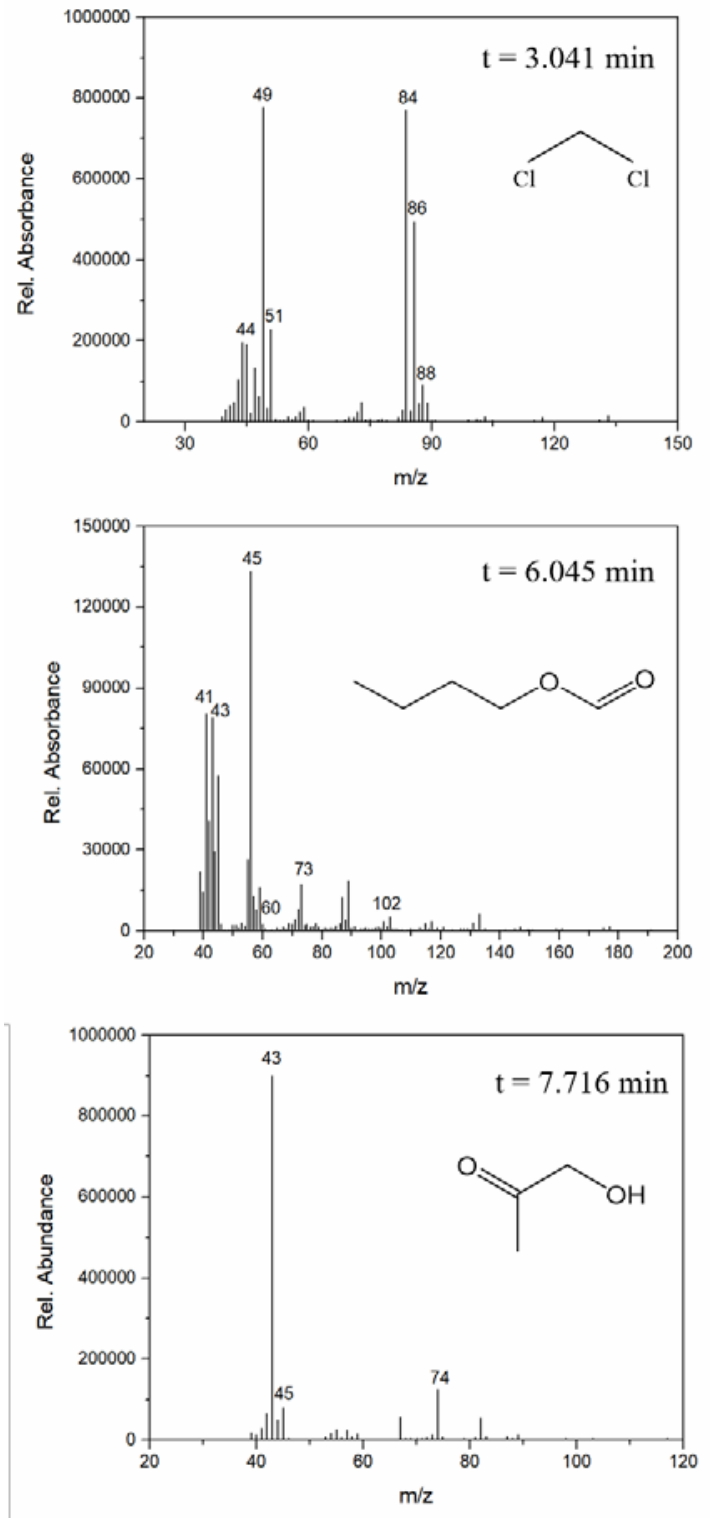

Figure S5: GC-MS spectra of gas phase products formed from the photooxidation of furan. 

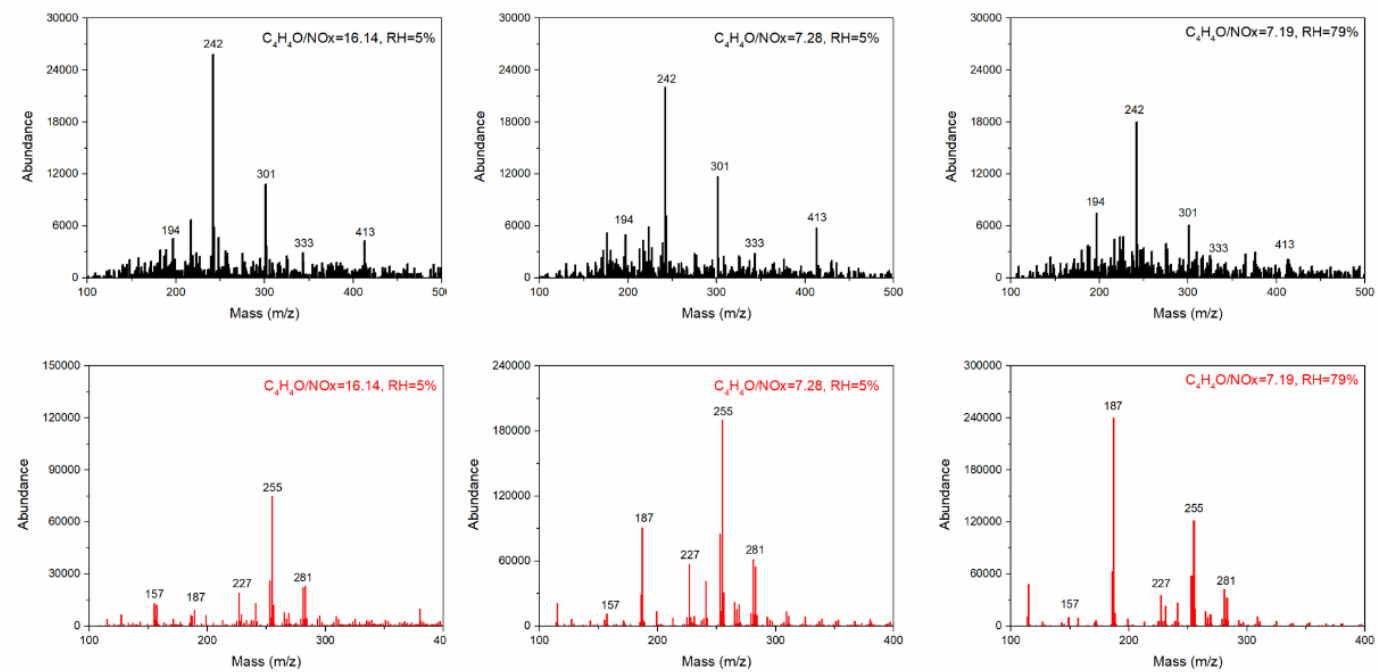

Figure S6: Background-subtracting mass spectra of SOA in both positive ion mode (black) and negative ion mode (red) from the photooxidation of furan under different experimental conditions. 